\title{
PERSONALIDAD Y ELECCIÓN DE PERSONAJE EN LOS JUEGOS DE ROL: DIME QUIÉN ERES Y TE DIRÉ QUIÉN PREFIERES SER
}

Resumen: Los juegos de rol son una forma de ocio en la que un conjunto de jugadores participa en un sistema de creación de historias episódicas y participativas. La personalidad es un constructo que ha mostrado su influencia en la toma de decisiones de múltiples aspectos de la vida, y en este estudio comprobamos si se relaciona con la elección de personaje. Se contó con cincuenta y siete jugadores de rol que cumplimentaron un cuestionario acerca del juego de rol Dungeons \& Dragons. Los resultados muestran diferencias en la elección de la clase de personaje según los factores de personalidad Apertura a la Experiencia, Amigabilidad y Extraversión. Junto a ello, se examinan las asociaciones existentes entre personalidad y preferencia de determinados tipos de partidas de rol. Finalmente, se reivindica la realización de más investigaciones que contribuyan a conocer la relación entre personalidad y elección de personaje en los juegos de rol.

Palabras clave: personalidad; juegos de rol; toma de decisiones.

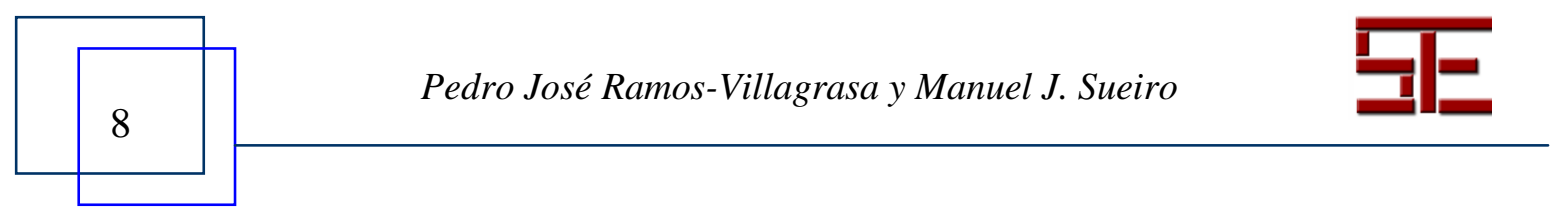




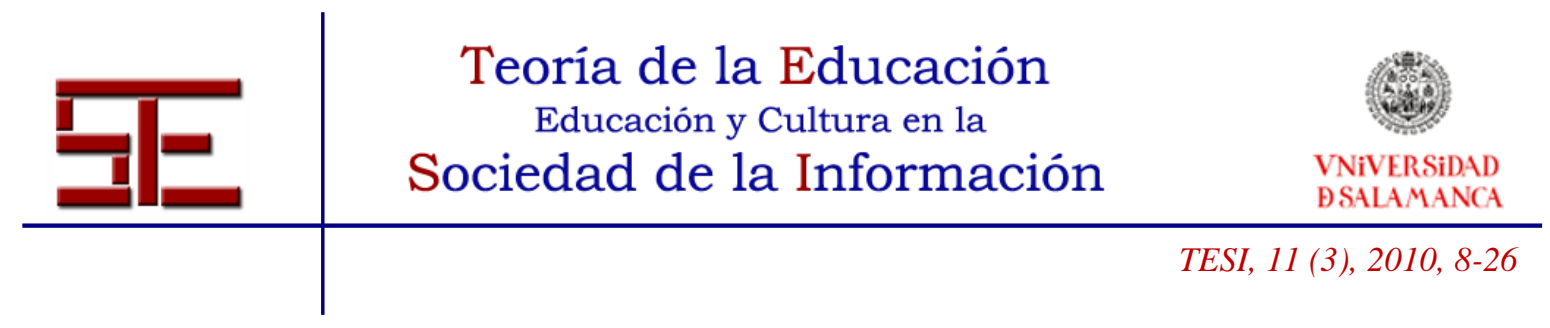

\title{
PERSONALITY AND CHARACTER PREFERENCE IN ROLE-PLAYING GAMES
}

\begin{abstract}
In role-playing games players perform participative and episodic stories. Personality is a psychological construct associated with decision processes in many aspects of life. In this study, we analyzed if Big Five Personality Factors were related to game character preferences in the role-playing game Dungeons \& Dragons. Results show that Personality is related only in the decision of character's class. We also study the relationship between Personality and plots in role-playing games (action, intrigue, mystery, and personal relationships). Finally, recommendations to further investigation were given.
\end{abstract}

Key words: role-playing games; decision processes.

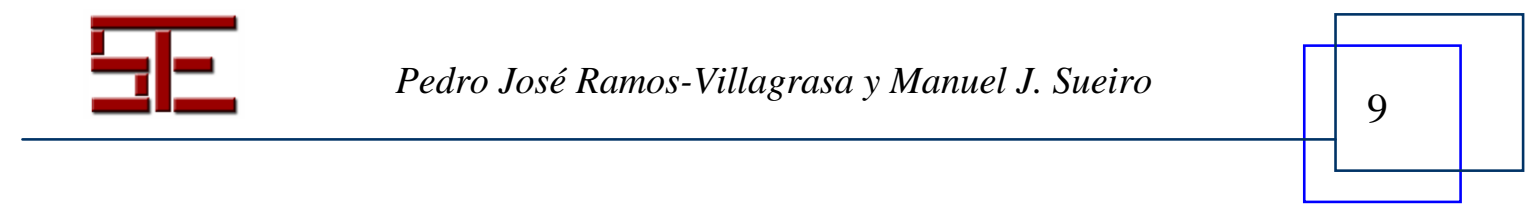




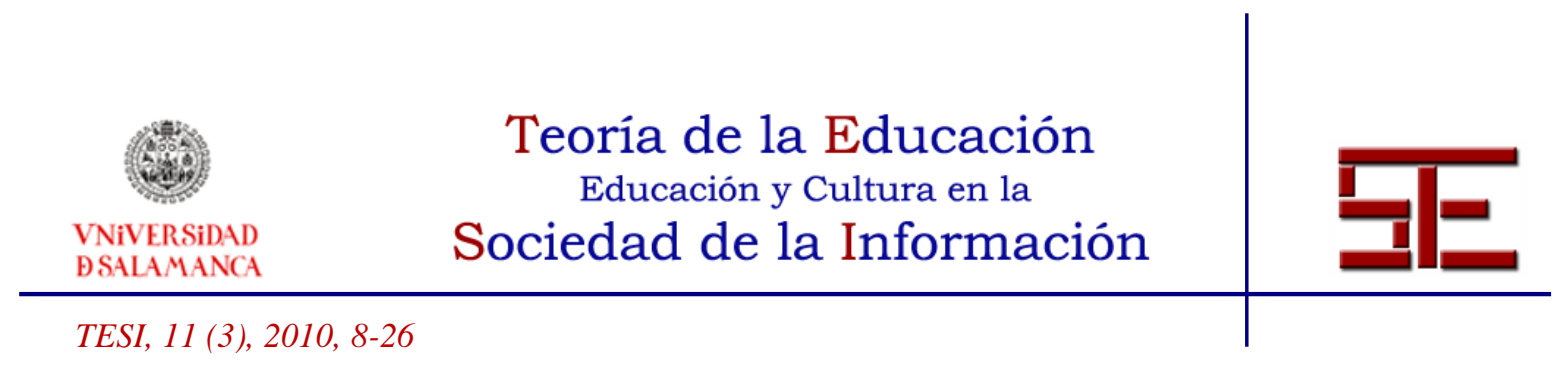

\section{PERSONALIDAD Y ELECCIÓN DE PERSONAJE EN LOS JUEGOS DE ROL: DIME QUIÉN ERES Y TE DIRÉ QUIÉN PREFIERES SER}

Fecha de recepción: 20/04/2010; fecha de aceptación: 14/09/2010; fecha de publicación: 30/11/2010

Pedro José Ramos-Villagrasa

pramosvi7@docd4.ub.edu

Universidad de Barcelona

Manuel J. Sueiro

msueiro@gmail.com

Universidad Complutense de Madrid

\section{1.- LOS JUEGOS DE ROL}

Los juegos de rol son una forma de ocio que ha estado rodeada de interés y polémica a partes iguales. Existe consenso al considerar Dungeons \& Dragons de Gygax y Anderson (1974) el primer juego de rol. En él, los jugadores simulan ser héroes en un mundo de fantasía similar a los que pueden encontrarse en el subgénero literario de ficción denominado literatura fantástica. Como tales héroes, se adentran en cubiles, mazmorras y guaridas de criaturas malvadas para derrotarlas y así conseguir realizar grandes gestas a la vez que incrementan el poder de sus personajes, por ejemplo, mediante objetos mágicos o el aprendizaje de nuevas habilidades y conjuros.

Con el paso del tiempo el concepto de juego de rol se popularizó, y a la vez que Dungeons \& Dragons se desarrollaba nacieron otros juegos también sustentados en la simulación de personajes, pero basados en otros géneros como la ciencia ficción o el terror. En la actualidad incluso se diferencian los juegos de rol tradicionales (apodados "de papel y lápiz") de otras variantes o formas de ocio relacionadas como los juegos de rol en vivo o los videojuegos catalogados "de rol". Una revisión del concepto de juego de rol y sus diferentes modalidades puede encontrarse en Hitchens y Drachen (2008).

Mackay (2001) define los juegos de rol como un sistema de creación de historias episódicas y participativas que, amparándose en reglas, permite a un grupo de jugadores $\mathrm{y}$ un director de juego determinar cómo se resuelven las interacciones entre los personajes que interpretan.

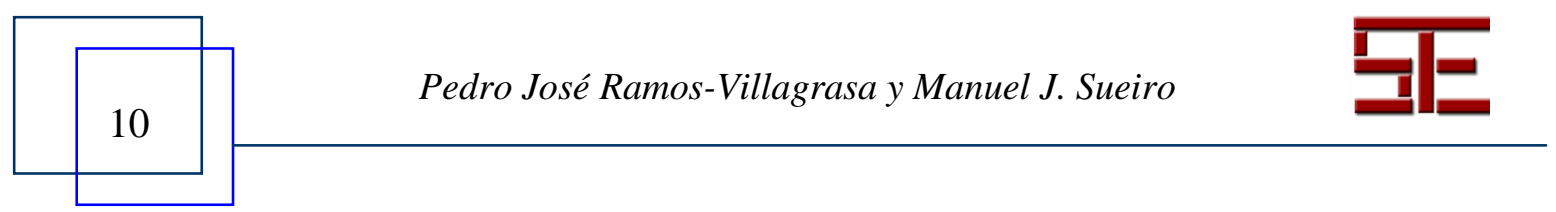




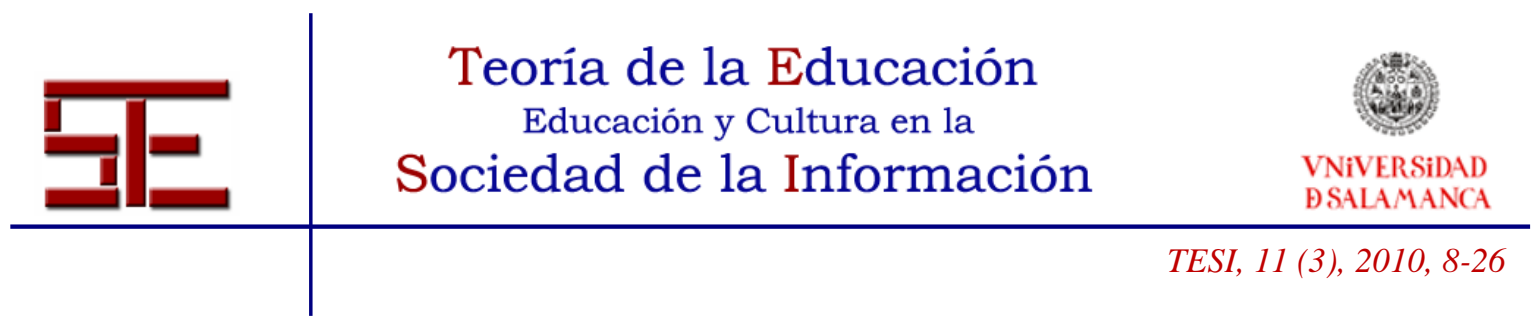

La definición de Mackay (2001) nos resulta especialmente apropiada pues resalta las características definitorias de los juegos de rol frente a otros tipos de ocio: en primer lugar, enfatiza que los juegos de rol se basan en la creación de historias; en segundo lugar, que la creación de historias es participativa; en tercer lugar, resalta la existencia de un reglamento que regula el juego; en cuarto lugar, diferencia los dos tipos de jugadores que suelen encontrarse en los juegos de rol: los "jugadores", que interpretan los personajes protagonistas, y el director de juego, que interpreta a los personajes secundarios, propone una trama y asegura el cumplimiento de las reglas establecidas; por último, refiere el modo en que todos los elementos se conjugan -personajes principales y secundarios que interactúan y que, según lo indicado en las reglas, se determina el resultado de dichas interacciones-para dar lugar a la narración.

Una partida de rol no puede realizarse sin la creación de "personajes jugadores", los personajes ficticios que los jugadores desean interpretar. Cada juego de rol determina, dentro de su ambientación, qué tipo de personajes jugadores resultan apropiados, de manera que en un juego ambientado en la Edad Media española no será procedente interpretar un vaquero, al igual que tampoco lo será interpretar un técnico de laboratorio en una historia ambientada en el Imperio Romano.

\section{1.- La investigación acerca de los juegos de rol}

El interés de los investigadores por los juegos de rol hasta el momento no ha sido amplio, pero sí diverso. La razón posiblemente se encuentra en la escasa difusión de este tipo de juegos, de hecho, la mayor parte de artículos se han publicado después de crímenes o suicidios que los medios de comunicación vincularon a los juegos de rol, como el caso de Javier Rosado producido en 1994 en España, más popularmente conocido como "Crimen del Rol".

Aunque posteriormente se probara que ninguno de estos casos tenía una relación directa con los juegos de rol, la opinión pública los ha asociado con la criminalidad, el satanismo y los comportamientos vandálicos. Como indican Esteban y Vecina (1999) esto puede explicarse por la tendencia de las personas a explicar la conducta anómala o aberrante basándose en los factores más inusuales o desconocidos, como eran en aquel momento los juegos de rol. En este sentido destacamos el estudio de Leeds (1995), el cual trató de probar que los juegos de rol eran un precursor del satanismo, hipótesis que no fue confirmada en su estudio el cual, además, mostró que satanistas y jugadores de rol tenían características de personalidad y creencias muy diferentes entre sí.

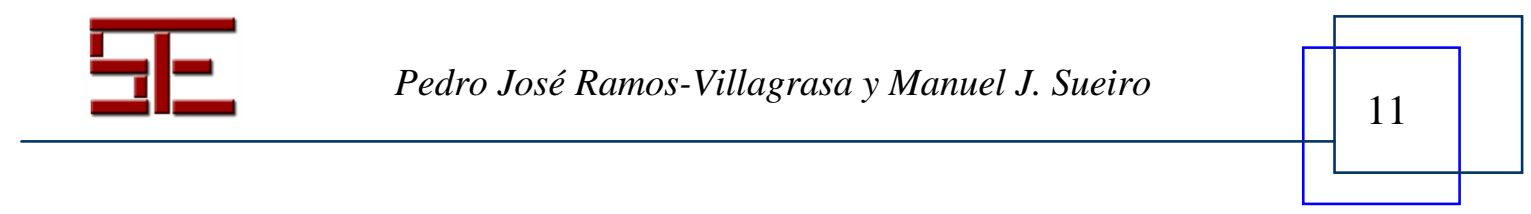




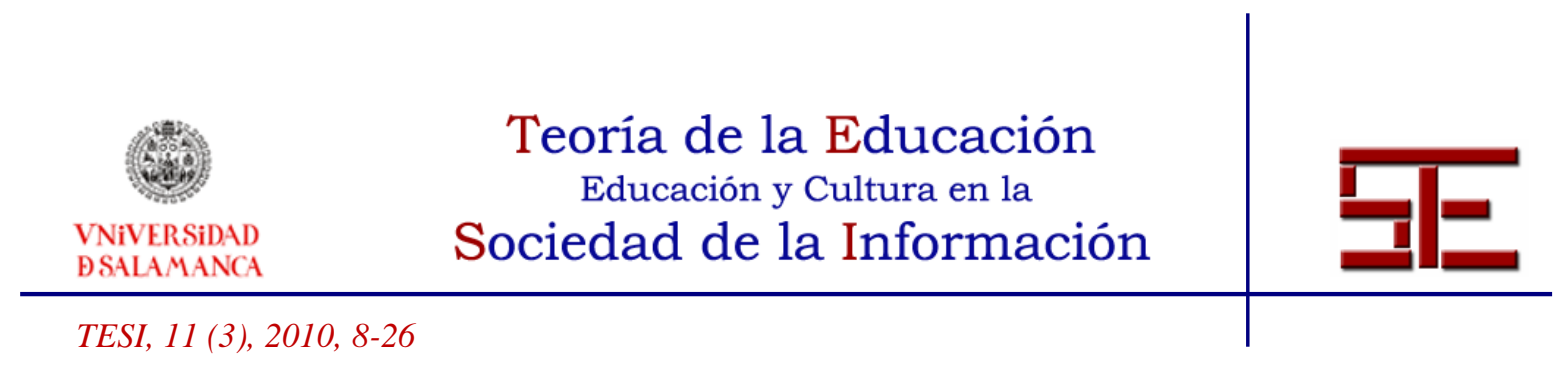

Lo que la investigación ha mostrado acerca de los jugadores de rol es que éstos tienen una elevada capacidad de imaginación y empatía (Rivers, 2007) y que el desarrollo social y cognitivo de los adolescentes que juegan a rol es similar a los que no lo hacen (Esteban y Vecina, 1999), salvo en el caso de las mujeres donde las no jugadoras muestran una mayor ansiedad social/timidez respecto a las jugadoras. También se ha documentado la posibilidad de utilizar juegos de rol como parte de una psicoterapia (Enfield, 2007), como una herramienta formativa (Camargo, Jacobi y Ducrot, 2007) o de intervención social (Esteban y Vecina, 1999), entre otros.

El único estudio que ha mostrado una relación que apoye los prejuicios acerca de los juegos de rol es el de Simon (1998), que encuentra una asociación entre los años como jugadores del juego de rol Vampiro: La Mascarada y la conducta antisocial, si bien debemos recordar que la correlación no implica una relación de causalidad, esto es, que basándonos únicamente en un estudio y en su metodología empleada no podemos asumir que esa relación no pueda deberse a otras causas. De hecho, en una línea de investigación similar, Abyeta y Forest (1991) no encuentran relación alguna entre jugar a rol y realizar actos delictivos.

En definitiva, aún necesitamos más investigación acerca de los aspectos psicológicos de los juegos de rol. En la actualidad estamos experimentando un interés emergente por los juegos de rol desde el punto de vista académico. Estas nuevas investigaciones se interesan tanto por comprender mejor los aspectos psicológicos, sociológicos e incluso literarios que rodean el juego de rol (v. g. Dyszelski, 2006; Hammer, 2007; Hitchens y Drachen, 2008; Park y Henley, 2007), como por estudiar formas de ocio vinculadas a los juegos de rol que tienen un mayor número de aficionados, como los videojuegos de rol multijugador o MMORPG (v. g. Cole y Griffiths, 2007; De freitas y Griffiths, 2007; Hsu, Kao y Wu, 2007).

\section{LA ELECCIÓN DE PERSONAJE EN LOS JUEGOS DE ROL}

Un aspecto de especial interés desde la psicología es comprender qué lleva a un jugador a elegir desempeñar un personaje determinado en un juego de rol. A diferencia del teatro, donde sus características físicas pueden determinar qué tipo de papeles puede adoptar, en los juegos de rol cualquier persona puede interpretar cualquier personaje, al menos dentro de las posibilidades de la ambientación en que se esté jugando. Estos

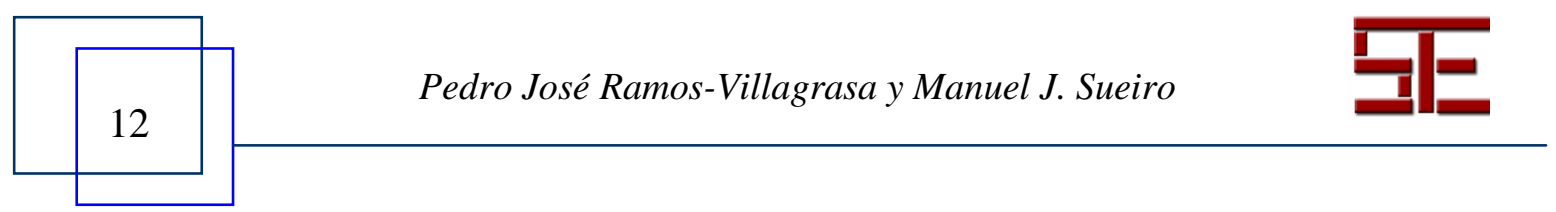




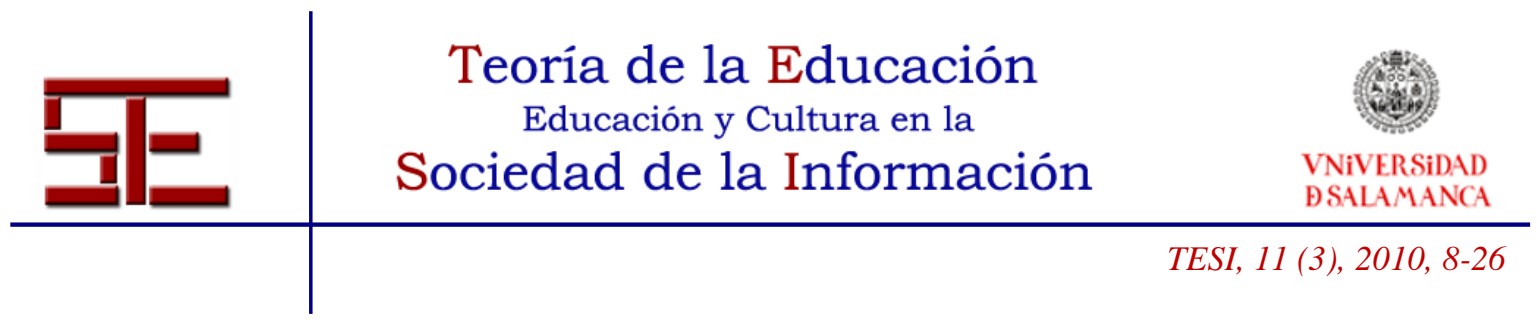

personajes deberán definirse en los términos delimitados por las reglas del juego y, también, en una historia del personaje como si se tratara de una biografía, explicando cómo ha sido la vida del personaje ficticio en la ambientación hasta el momento de iniciarse la historia.

En algunos juegos de rol se utiliza el azar para determinar los rasgos definitorios de un personaje, pero en la mayoría de ellos, como en Dungeons \& Dragons, es el propio jugador quien decide qué interpretar. Por tanto, crear un personaje jugador para una partida de rol es, en esencia, un proceso de toma de decisiones en el que el jugador opta por unas combinaciones u otras de rasgos según el personaje que desee interpretar.

\section{1.- La elección de personaje en Dungeons \& Dragons}

En primer lugar es preciso aclarar que según la edición del juego que utilicemos existen diferentes opciones de elección de personaje, por lo que en este trabajo nos centraremos en la más popular en España en la actualidad, Dungeons \& Dragons 3.5 (Tweet, Cook y Williams, 2003; Cook, Williams y Tweet, 2003; Williams, Tweet y Cook, 2003), asumiendo únicamente la utilización de los tres manuales básicos para el juego, llamados "Manual del Jugador" (donde se describen las reglas básicas del juego, incluyendo la creación de personajes jugadores), "Guía del Dungeon Master" (dedicada al director de juego, que en este juego se conoce con el apelativo de Dungeon Master) y "Manual de Monstruos" (una descripción de criaturas para ser empleadas como enemigos de los protagonistas). Algunos libros posteriores destinados a ampliar el juego ofrecen versiones opcionales o ampliaciones de las opciones que vamos a incluir en el estudio.

En Dungeons \& Dragons el jugador debe realizar una serie de elecciones fundamentales para crear al personaje jugador que interpretará en el juego. Se trata de elegir la "raza" y la "clase" de su personaje, así como asignar los valores determinados a las seis "características". Desarrollaremos estos conceptos a continuación.

La "raza" hace referencia a la especie a la que pertenece el personaje. En los mundos de fantasía es normal que los humanos convivan con otras especies ficticias como los elfos o los enanos. La elección de raza garantiza al jugador ciertas ventajas para su personaje: por ejemplo, los elfos pueden ver en la oscuridad, mientras que los humanos saben

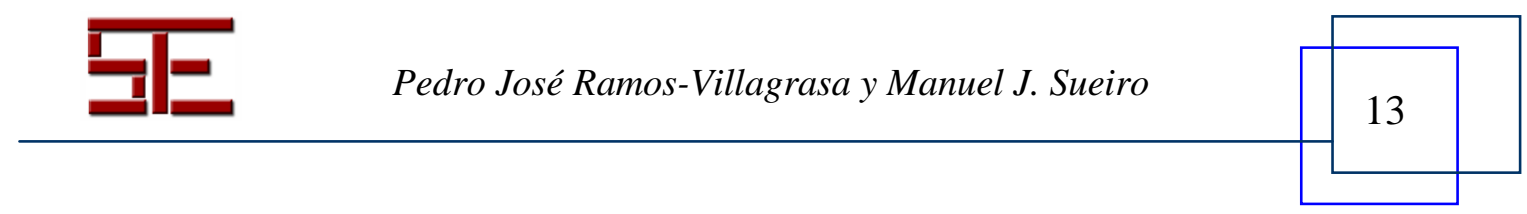




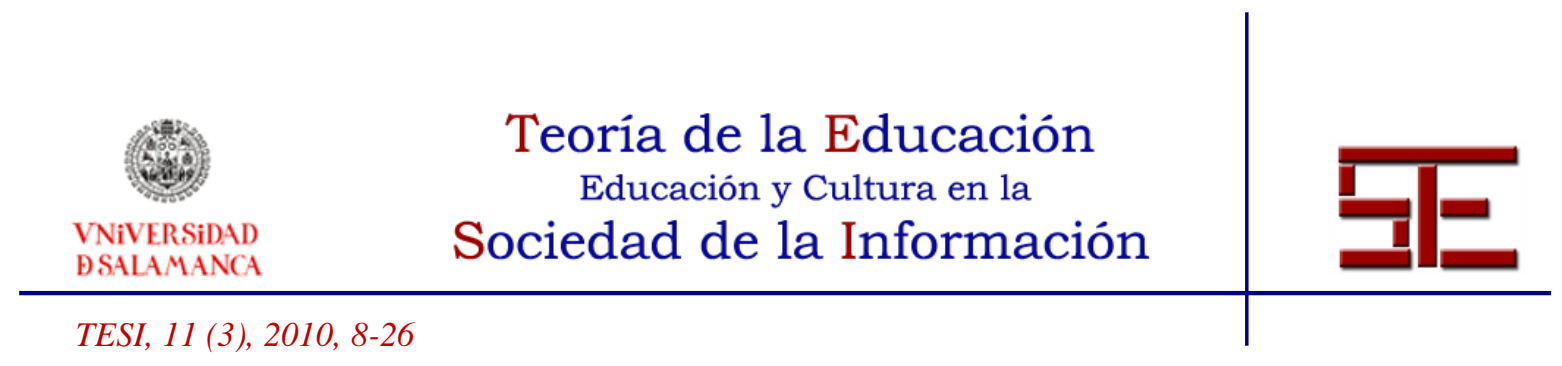

hacer más cosas (poseen más puntos de habilidad, en términos de juego) que el resto de razas. Desde el punto de vista interpretativo las razas también ofrecen diferentes formas de ver la vida y de interacción entre sí que el jugador deberá interpretar. En $D \& D$ las razas disponibles para los jugadores son: humano, elfo, gnomo, mediano, semielfo y semiorco.

Por lo que respecta a la "clase", ésta determina la ocupación del personaje, que siempre será de carácter heroico, desde un guerrero a un mago. La elección de la ocupación es el eje fundamental de la creación de un personaje al determinar qué cosas sabrá hacer y en qué grado, como pelear, moverse sin ser detectado, lanzar conjuros, etc. En $D \& D$ las clases de personaje disponibles son: bárbaro, bardo, clérigo, explorador, hechicero, guerrero, mago, paladín y pícaro.

Por último, las "características" son valores de juego que todo personaje posee y que sirven como principal representación del mismo. Son seis: fuerza, destreza, constitución, inteligencia, sabiduría y carisma. Al crear su personaje el jugador debe asignarle una puntuación a cada característica, disponiendo de diversos métodos para hacerlo. Ciertas características son de mayor importancia para determinadas clases de personaje, como la fuerza para un guerrero o la inteligencia para un mago, por lo que normalmente guardan relación entre sí.

A partir de las elecciones realizadas en estos cuatro rasgos, el jugador sólo debe aplicar lo indicado en las reglas del juego para construir su personaje al completo. Después, deberá complementar los rasgos de juego con su interpretación durante la partida.

\section{3.- LA PERSONALIDAD Y SU INFLUENCIA EN LA TOMA DE DECISIONES}

La personalidad es un constructo que se ha convertido en básico dentro de la psicología y que hace referencia a "la organización dinámica, dentro del individuo, de los sistemas psicofísicos que determinan sus ajustes únicos al ambiente” (Allport, 1937, 48).

Uno de los modelos de personalidad con más difusión es el modelo de los "Cinco Grandes" o Big Five, que determina que la personalidad puede dividirse en cinco componentes fundamentales: "Neuroticismo", que caracteriza a personas preocupadas, inseguras, temperamentales, ansiosas, depresivas, etc.; "Extraversión", que caracteriza a personas como sociables, amistosas, habladoras, asertivas, con buen humor, etc.; "Apertura a la experiencia", que caracteriza a personas originales, imaginativas,

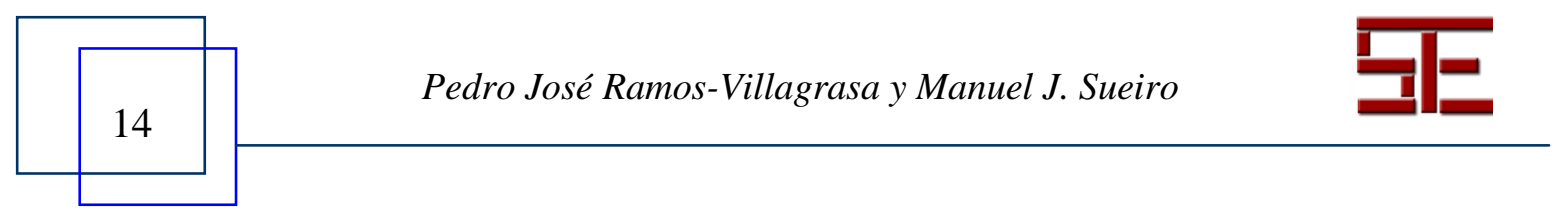




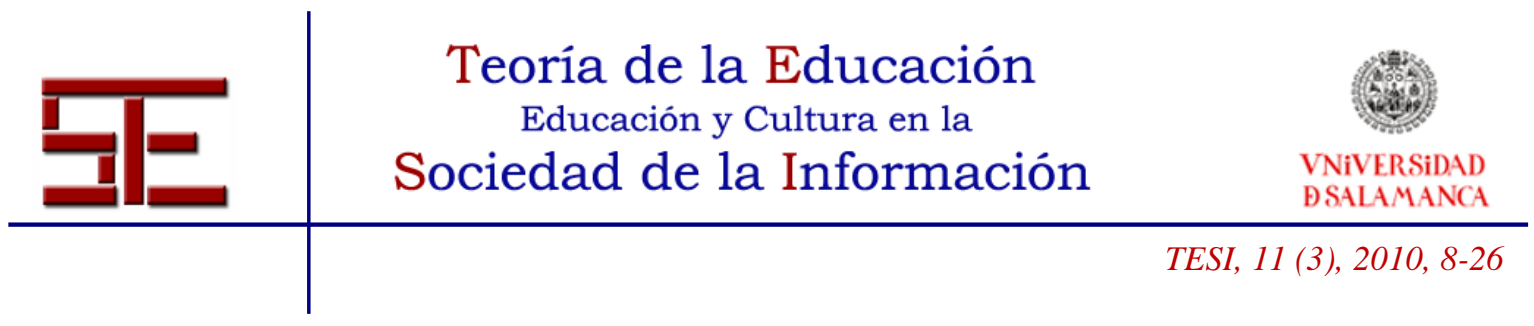

deseosas de probar cosas nuevas, con variados intereses y sentimientos estéticos; "Responsabilidad", que caracteriza a personas prudentes, controladas, respetuosas y planificadas; el último factor es "Amigabilidad", que caracteriza a personas sensibles, amables y comprensivas. Todas las personas poseen los "Cinco Grandes" en alguna medida, si bien en unas unos factores predominan sobre los demás.

Aunque se han identificado limitaciones en el modelo (Benet-Martínez, 1997; Block, 1995; John y Robins, 1993), existe acuerdo respecto a su solidez (Goldberg, 1990; John, 1990). De hecho, ha sido utilizado para explicar la influencia de la personalidad en muchos ámbitos, como el escolar, el laboral o el clínico.

Uno de los aspectos donde la personalidad ha mostrado su influencia es en la toma de decisiones de cualquier tipo. Tenemos ejemplos en la decisión de cambiar de trabajo (Zimmerman, 2008), tener hijos (Jokela, Kivimäki, Elovainio y Keltikangas-Järvinen, 2009), la música que escuchamos (Rentfrow y Gosling, 2003), nuestra intención de voto (Schoen y Schumann, 2007) y, también, en el tipo de personaje jugador que asumimos en un juego de rol (Hsu et al., 2007; Park y Henley, 2007).

\section{4.- EL PRESENTE ESTUDIO}

Nuestra investigación continúa la línea acerca de la influencia de la personalidad del jugador de rol en la creación de sus personajes jugadores de trabajos como los de Hsu et al. (2007) y Park y Henley (2007).

En nuestro caso circunscribimos la investigación a un juego de rol en concreto, Dungeons \& Dragons versión 3.5, para proporcionar a los participantes un marco de referencia conocido y utilizado por ellos mismos, en lugar de categorías creadas ad hoc para el estudio como en el trabajo de Hsu et al. (2007) o de un videojuego online como en el caso de Park y Henley (2007) que, a pesar de contar con una adaptación a juego de rol "de lápiz y papel", realmente es una adaptación del sistema de Dungeons \& Dragons a la ambientación del videojuego.

Junto a ello, esta investigación también ahonda en la relación entre la personalidad y la preferencia por historias con un determinado tipo de argumento (acción, intriga, misterio, relaciones interpersonales).

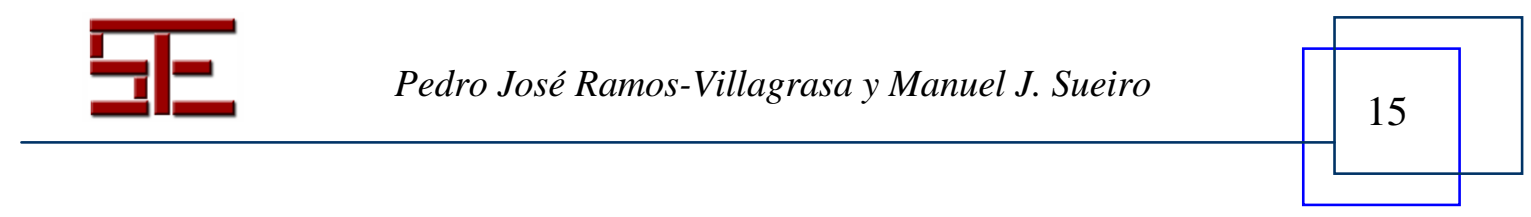




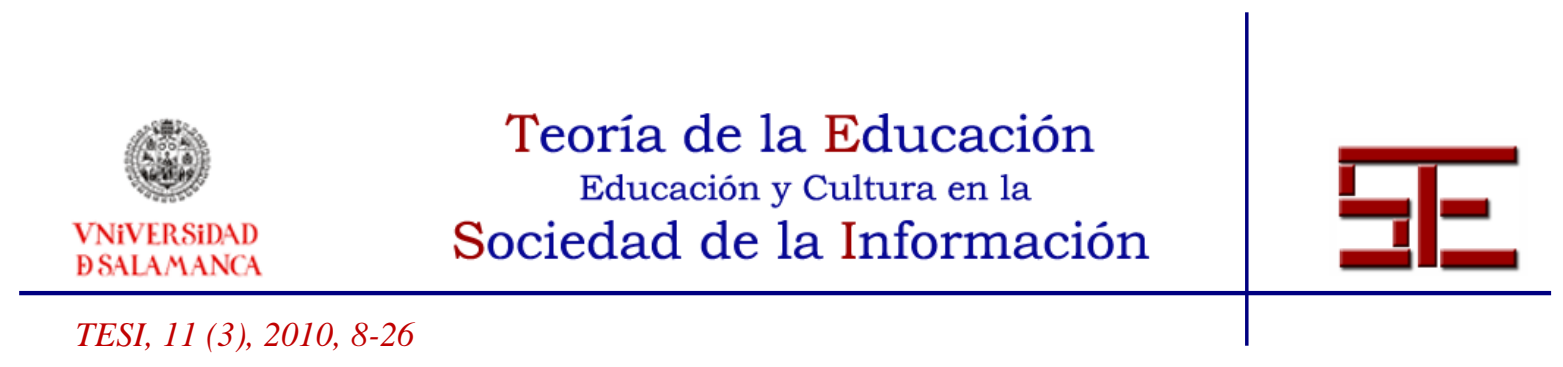

Consideramos que los jugadores interpretan personajes de acuerdo con su personalidad (Park y Henley, 2007), por lo que nuestras hipótesis son las siguientes:

H1: Los factores de personalidad se asociarán con la elección de la raza del personaje jugador.

H2: Los factores de personalidad se asociarán con la elección de la clase del personaje jugador.

H3: Los factores de personalidad se asociarán con la preferencia de características del personaje jugador.

Dado que, además, en un juego como Dungeons \& Dragons las elecciones de raza, clase y características del personaje jugador pueden dar lugar a personajes más o menos ventajosos, planteamos la cuarta hipótesis en los siguientes términos:

H4: La elección de raza, clase y características del personaje jugador estarán relacionadas entre sí.

Por último, creemos que, análogamente a la elección de personaje, la personalidad debe jugar algún papel en la elección de argumentos, si bien la investigación realizada hasta el momento no ha tratado esta cuestión.

H5: Los factores de personalidad se asociarán con los diferentes tipos de argumento para las partidas de rol.

\section{5.- MÉTODO}

\subsection{Participantes}

Participaron en el estudio 57 personas jugadoras habituales de rol, con el requisito de haber jugado alguna vez a Dungeons \& Dragons. La media de edad fue de 27,76 años y la desviación típica de 5,02 (mínimo 16, máximo 39 años). El 87,7\% de los sujetos eran varones, algo esperable ya que el rol continúa siendo una afición mayoritariamente masculina aunque el número de jugadoras se incremente progresivamente (Dyszelski, 2006). Respecto al nivel de estudio, la mayoría contaba con estudios universitarios $(59,6 \%)$, seguido de los sujetos con estudios secundarios $(38,6 \%)$ y el resto $(1,8 \%)$

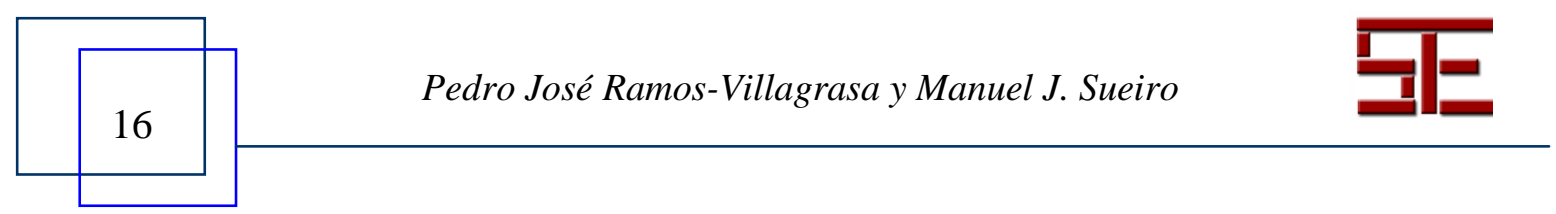




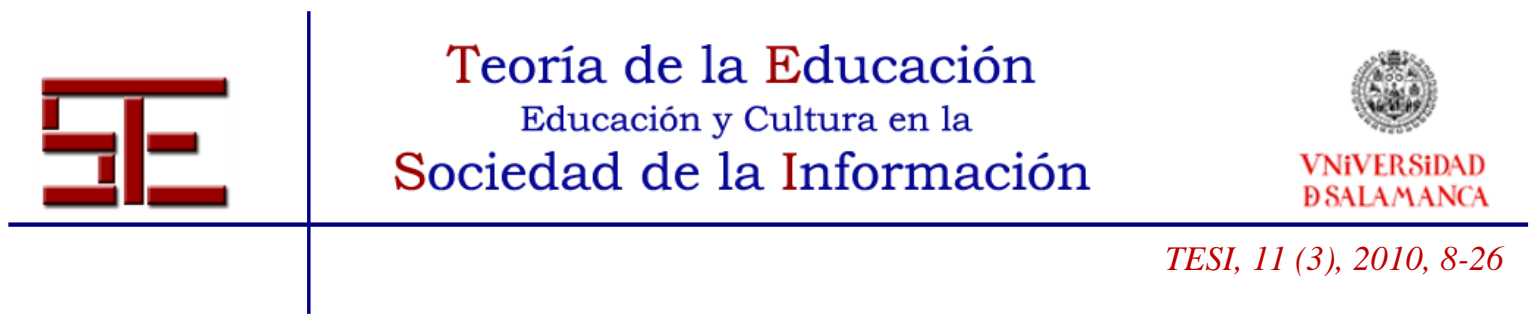

estudios primarios. Respecto a la situación laboral, el 64,9\% de los participantes eran trabajadores activos, mientras que el $22,8 \%$ eran estudiantes y el resto se encontraba en situación de desempleo en el momento de aplicación del cuestionario.

Los participantes informaron llevar una media de 13,02 años jugando al rol y en concreto 8,75 años jugando a Dungeons \& Dragons. Respecto a la frecuencia de juego, el $47,4 \%$ informó que jugaba una vez por semana, un 10,5\% lo hacía más a menudo (al menos dos o tres veces por semana), mientras que el resto jugaba con menor asiduidad (una vez al mes o incluso menos).

\subsection{Variables e instrumentos}

Los factores de personalidad "Big Five" fueron medidos con la versión en castellano del BFI de Bennet-Martínez y John (1998), elaborada por los propios autores. Cuenta con cuarenta y cuatro ítems, de los cuales ocho miden Neuroticismo, ocho miden Extraversión, diez Apertura a la experiencia, nueve Amigabilidad y los nueve restantes Responsabilidad. Un ejemplo de ítem es "Es minucioso/a en el trabajo". Las respuestas se midieron mediante escala tipo Likert de cinco puntos, desde "Muy en desacuerdo" hasta "Muy de acuerdo".

Además, empleamos un cuestionario creado ad hoc para este estudio en el que se indagaba acerca del número de años jugando a rol, número de años jugando a $D \& D$, elección preferida de raza y clase de personaje, ordenación por relevancia de las seis características de personaje, y ordenación por preferencia de los argumentos para las partidas de rol. Junto a ello, se recabó información sobre variables sociodemográficas como el sexo o la edad de los participantes.

\subsection{Procedimiento}

Los datos se recogieron aprovechando la celebración de unas jornadas de rol en el Principado de Asturias. Se abordó a los sujetos preguntándoles si querían participar en un estudio sobre los jugadores de rol que estaban realizando las universidades de Barcelona y Complutense de Madrid. Se especificaba en ese momento que la única condición para participar en el estudio era haber jugado alguna vez a Dungeons \& Dragons. A continuación, se facilitaba a los sujetos un ejemplar del cuestionario, que

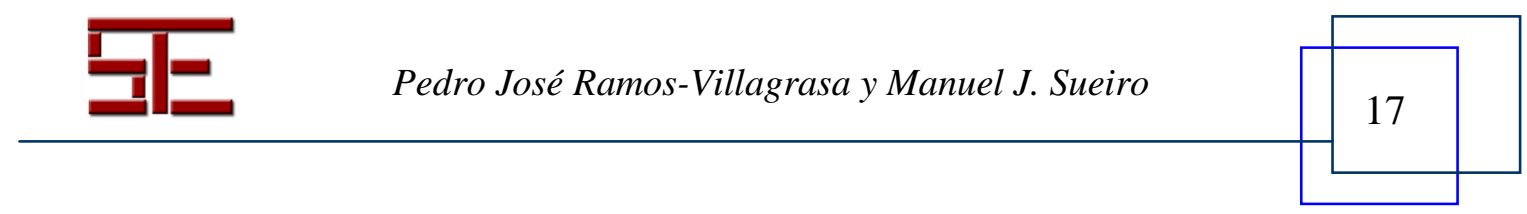




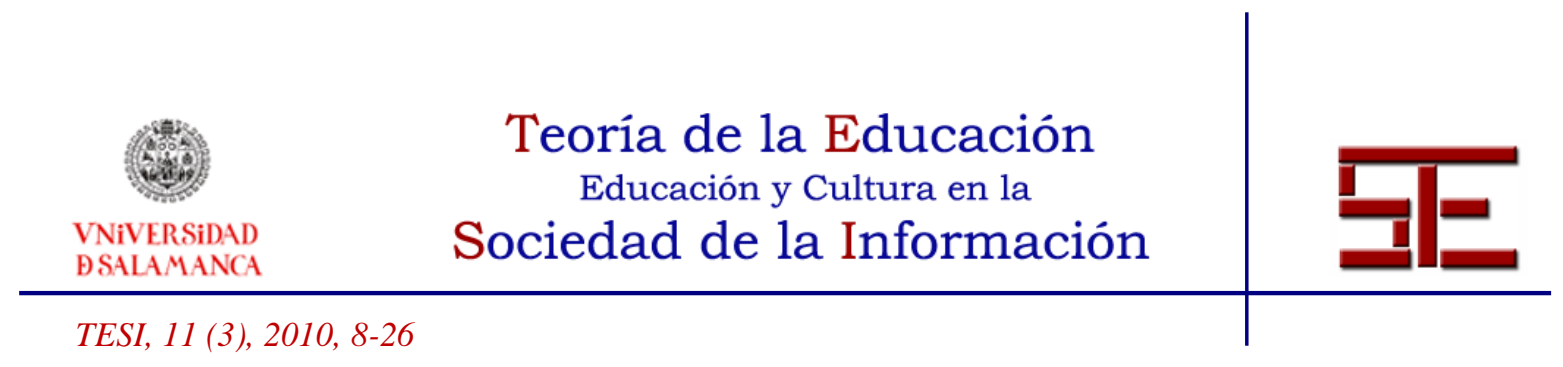

incluía instrucciones precisas de cumplimentación y los correspondientes instrumentos. Adicionalmente, se hacía hincapié a los sujetos en que rellenaran el cuestionario de manera seria e individual, recordándoles que los cuestionarios eran completamente anónimos. Los investigadores se encargaron de recoger los cuestionarios conforme los participantes iban terminando, agradeciéndoles su colaboración nuevamente.

Los datos se analizaron con SPSS 15 para Windows, utilizando análisis multivariado de la varianza, estudio de la matriz de correlaciones y tablas de contingencia, en función de las diferentes escalas de medida de las variables.

\section{RESULTADOS}

El reducido tamaño de la muestra obligó a recodificar las elecciones de raza y clase de personaje en categorías relacionadas, con la finalidad de maximizar el número de sujetos en cada grupo para poder utilizar técnicas paramétricas de análisis.

En el caso de la raza los grupos se crearon siguiendo el origen que tienen éstas dentro de la ambientación: el grupo 1 se creó para las razas no humanas y no relacionadas con lo feérico, como son los enanos y los gnomos; el grupo 2 se compuso de las razas feéricas (elfo y gnomo), el grupo 3 exclusivamente por humanos, y finalmente el grupo 4 por las dos razas semihumanas del juego, concretamente semielfo y semiorco. Por lo que respecta a las clases, se les dividió por los roles que suelen desempeñar en las aventuras: el grupo 1 estaba compuesto por lanzadores de conjuros arcanos (hechicero y mago), el grupo 2 por personajes especializados en el sigilo, el grupo 3 por clases que suelen apoyar a las demás o tener un papel mixto (bardo, clérigo, druida y monje), y finalmente el grupo 4 por los especialistas en combate cuerpo a cuerpo y resistir los ataques enemigos (bárbaro, guerrero y paladín). La Tabla 1 resume la remodificación realizada en raza y clase de personaje.

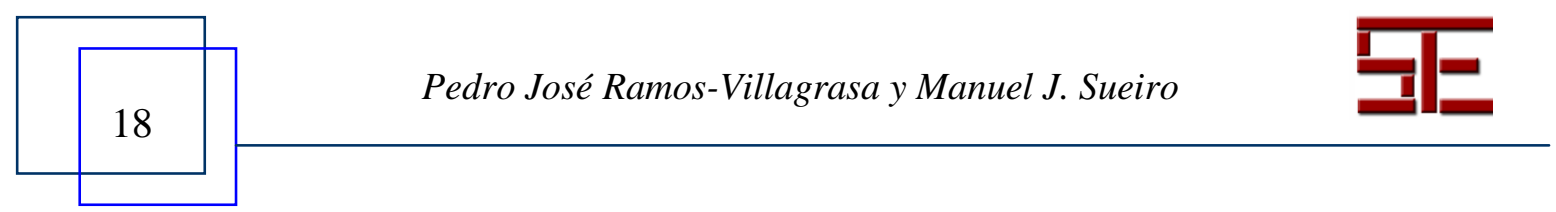




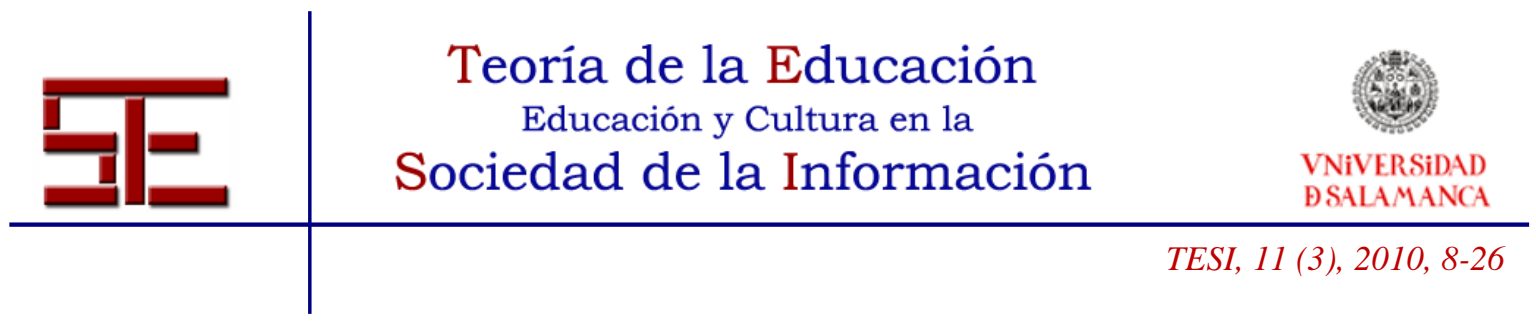

Tabla 1. Recodificación de las preferencias de raza y clase de personaje.

\begin{tabular}{cl}
\hline Preferencias de raza & \\
\hline Nivel recodificado & Preferencias \\
\hline 1 & Enano, Gnomo \\
2 & Elfo, Mediano \\
3 & Humano \\
4 & Semielfo, Semiorco \\
\hline Preferencia de clase & \\
\hline Nivel recodificado & Preferencias \\
\hline 1 & Hechicero, Mago \\
2 & Explorador, Pícaro \\
3 & Bardo, Clérigo, Druida, Monje \\
4 & Bárbaro, Guerrero, Paladín \\
\hline
\end{tabular}

Con estas categorías recodificadas como variables independientes se realizó análisis multivariado de la varianza (MANOVA) utilizando las puntuaciones en el BFI. Los resultados mostraron diferencias significativas según la clase de personaje en Apertura a la experiencia $(p<0,048)$, Extroversión $(p<0,008)$ y Amigabilidad $(p<0,021)$. No se hallaron diferencias significativas debidas a la elección de raza ni a la interacción. Por tanto, confirmamos la segunda hipótesis y rechazamos la primera y la tercera.

Utilizando la prueba de Scheffe para realizar comparaciones post hoc, se encontró que las diferencias estadísticamente significativas en las tres variables estaban entre los grupos 2 (pícaro y explorador) y 4 (guerrero y bárbaro), siempre a favor de este último.

A continuación, empleando los datos sobre preferencia por unas u otras características en el juego Dungeons \& Dragons, se crearon dos grupos de sujetos: aquellos con preferencia por las características físicas y aquellos con preferencia por las características mentales. No se encontraron diferencias estadísticamente significativas en las variables del BFI según esta nueva variable.

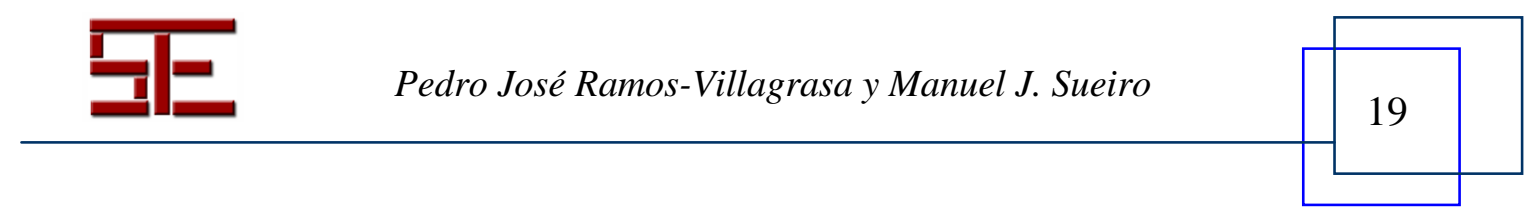




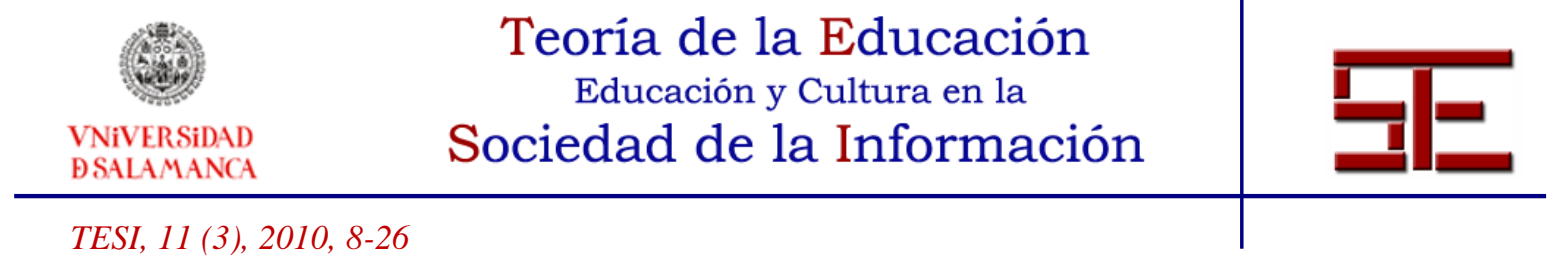

Se examinaron también las correlaciones entre diferentes aspectos medidos. En concreto, se examinó la correlación entre la importancia asignada a las características del personaje y el tipo de elementos de la partida. Sin embargo, las correlaciones fueron bajas, aunque se encontró significación estadística $(\mathrm{p}<0,05)$ en la relación entre características físicas y combate $(\mathrm{r}=0,311)$, mentales y combate $(\mathrm{r}=-0,311)$ y Sabiduría y combate $(r=-0,279)$. Un resumen de todas las correlaciones evaluadas puede verse en la Tabla 2.

Tabla 2. Matriz de correlaciones

\begin{tabular}{|c|c|c|c|c|c|c|c|c|c|}
\hline & $\begin{array}{l}\text { Apertura a la } \\
\text { Experiencia }\end{array}$ & GHQ & Extraversión & Amigabilidad & Responsabilidad & Combate & Intriga & Misterio & Relaciones \\
\hline Físicas & 0,09 & $-0,03$ & 0,16 & $-0,14$ & $-0,06$ & $\mathbf{0 , 3 1}$ & $-0,11$ & $-0,01$ & $-0,19$ \\
\hline Mentales & $-0,09$ & 0,03 & $-0,16$ & 0,14 & 0,06 & $-0,31$ & 0,11 & 0,01 & 0,19 \\
\hline Destreza & 0,09 & $-0,08$ & 0,12 & $-0,27$ & 0,00 & 0,19 & 0,07 & $-0,02$ & $-0,24$ \\
\hline Fuerza & $-0,00$ & 0,07 & 0,07 & $-0,06$ & $-0,10$ & 0,22 & $-0,24$ & 0,01 & 0,01 \\
\hline Constitución & 0,10 & $-0,07$ & 0,12 & 0,08 & $-0,01$ & 0,17 & $-0,00$ & $-0,00$ & $-0,17$ \\
\hline Inteligencia & $-0,00$ & $-0,08$ & $-0,04$ & 0,17 & $-0,07$ & $-0,11$ & 0,19 & $-0,04$ & $-0,04$ \\
\hline Sabiduría & 0,04 & 0,01 & 0,02 & 0,16 & 0,12 & $-0,28$ & $-0,02$ & 0,09 & 0,21 \\
\hline Carisma & $-0,20$ & 0,11 & $-0,26$ & $-0,08$ & 0,06 & $-0,15$ & 0,03 & $-0,04$ & 0,16 \\
\hline Combate & $-0,13$ & $-0,12$ & $-0,13$ & $-0,28$ & $-0,17$ & 1.00 & - & - & - \\
\hline Intriga & 0,21 & $-0,08$ & $-0,10$ & 0,29 & $-0,05$ & - & 1.00 & - & - \\
\hline Misterio & 0,12 & $-0,00$ & $\mathbf{0 , 3 0}$ & 0,01 & 0,12 & - & - & 1.00 & - \\
\hline Relaciones & $-0,21$ & 0,21 & $-0,06$ & $-0,02$ & 0,10 & - & - & - & 1.00 \\
\hline
\end{tabular}

Nota. Las correlaciones significativas aparecen en negrita $(\mathrm{p}<0.05)$

Junto a ello, se estudió la relación entre la preferencia por características físicas o mentales, las elecciones de raza y las elecciones de clase de personaje utilizando tablas de contingencia y el estadístico $\chi^{2}$ de Pearson. En la relación entre elección de raza y elección de clase de personaje, tanto el estadístico de Pearson $\left(\chi^{2}=12,647\right.$; gl=6; p <0,049) como la prueba de razón de verosimilitud ( $\mathrm{G} 2=17,429 ; \mathrm{gl}=6 ; \mathrm{p}<0,008)$ resultaron significativas estadísticamente, lo que nos lleva a concluir que existe relación entre las elecciones de raza y las de clase de personaje. El sentido de esta relación será discutido más adelante. En lo que se refiere a las preferencias de característica y la elección de raza no se encontró en cambio relación alguna. No así entre las preferencias de característica y la elección de clase, donde tanto $\chi^{2}\left(\chi^{2}=18,879 ; \mathrm{gl}=3 ; \mathrm{p}<0,001\right)$ como la razón de verosimilitud $(\mathrm{G} 2=19,394 ; \mathrm{gl}=3 ; \mathrm{p}<0,001)$ fueron estadísticamente significativas, mostrando una relación entre ambas variables. De esta forma podemos decir que la cuarta hipótesis se confirma parcialmente.

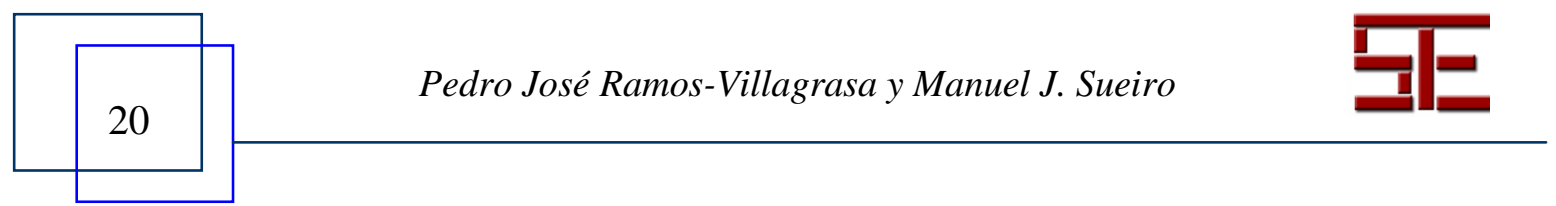




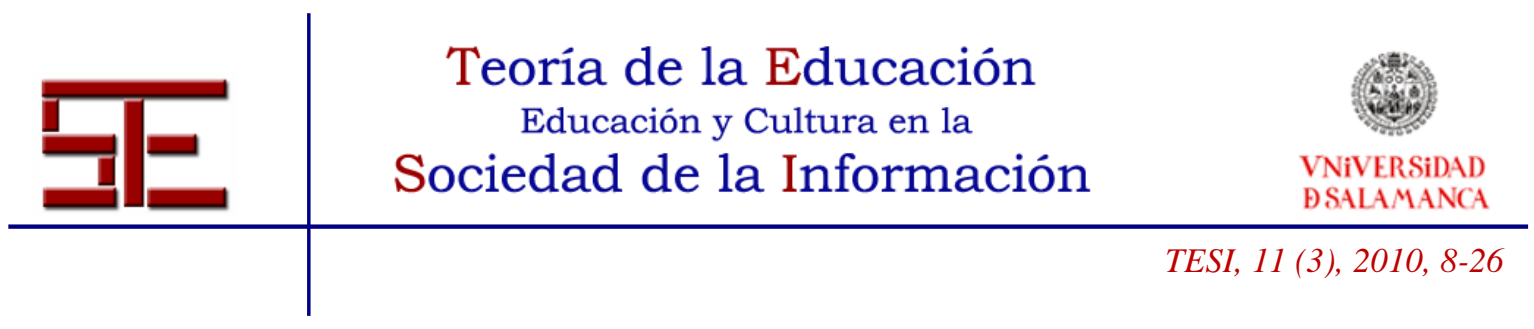

Finalmente, se hallaron las correlaciones entre las variables de personalidad y las elecciones de característica y preferencias por tipo de contenidos del juego (Intriga, Combate, Relaciones y Misterio). Sólo cuatro de estas correlaciones resultaron significativamente distintas de cero $(\mathrm{p}<0,05)$ : entre Amigabilidad y preferencia por la característica Destreza $(\mathrm{r}=-0,272)$, entre Amigabilidad y preferencia por el Combate $(\mathrm{r}=$ $-0,284)$, entre Amigabilidad y preferencia por la Intriga $(\mathrm{R}=0,288)$ y entre Extroversión y Misterio $(\mathrm{r}=0,299)$. De nuevo todas las correlaciones significativas fueron bajas, con un tamaño del efecto (medido mediante r2) menor a 0,09. Por ello, confirmar la quinta y última hipótesis.

\section{7.- CONCLUSIONES}

En este artículo hemos investigado la relación entre la elección de personaje en los juegos de rol y la personalidad. Los resultados han mostrado que, en nuestra muestra, únicamente uno de los tres elementos que determinan dicha elección se ve influido por la personalidad: la clase de personaje. Éste es el principal resultado de nuestro estudio.

La clase de personaje es, seguramente, el elemento fundamental de la creación de un personaje en $D \& D$ : un grupo de juego puede componerse por personajes de razas o distribuciones de características similares, pero para tener éxito normalmente necesitan repartirse las diferentes ventajas que dan las clases: necesitarán alguien capaz de sanar a sus compañeros (como un clérigo o un druida), alguien capaz de golpear fuertemente a los enemigos (como un guerrero o un bárbaro), alguien capaz de abrir cerraduras (como un pícaro) y así sucesivamente. Podría decirse que la clase de personaje es la elección que tiene un mayor reflejo en lo que el jugador hace durante el juego, y resulta relevante que ésta sea la única asociación significativa.

Más específicamente, hemos encontrado que son Apertura a la Experiencia, Extraversión y Amigabilidad los factores que diferencian de manera estadísticamente significativa la elección de clase de personaje, concretamente dichas diferencias se encuentran entre los grupos segundo (Pícaro y Explorador) y cuarto (Guerrero, Bárbaro, Paladín). El grupo cuarto es el que tiende a puntuar más alto en los tres factores de personalidad, resultados diferentes a los encontrados por Park y Henley (2007), si bien debemos tener en consideración que en dicho estudio se empleaban clases extraídas de un videojuego que no se corresponden exactamente con las de $D \& D$.

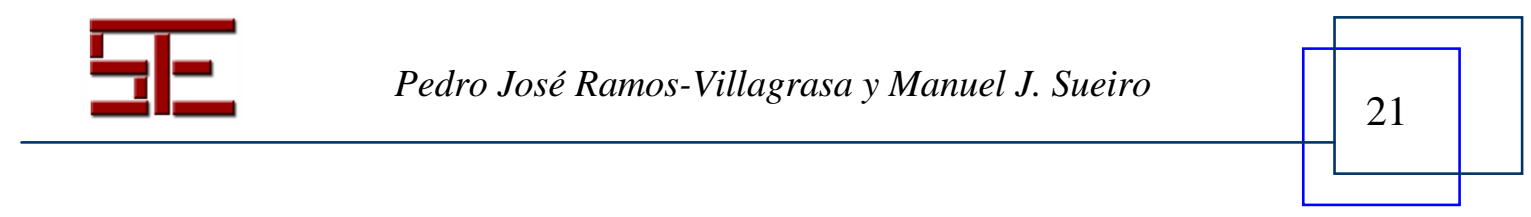




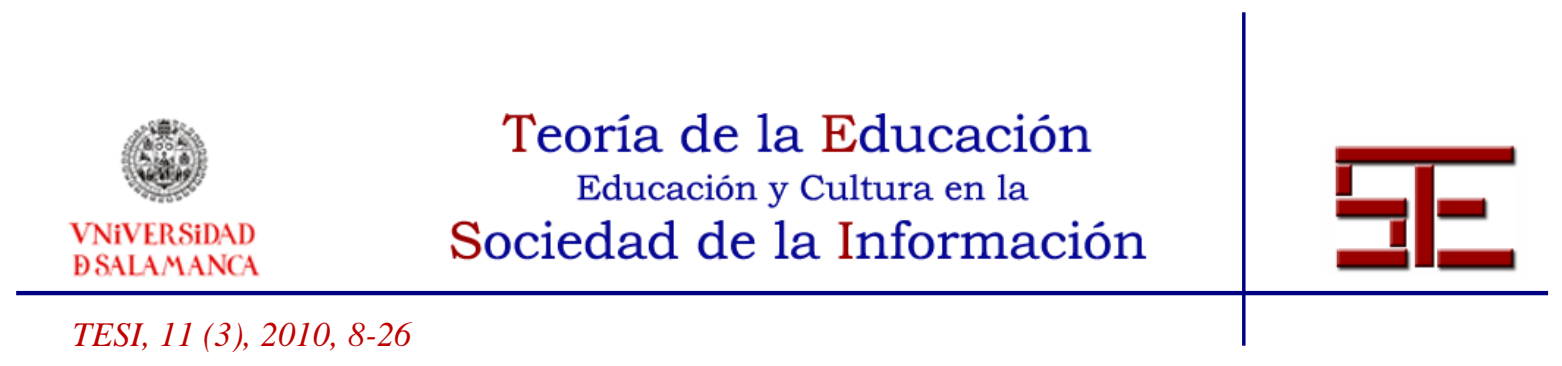

A pesar de que nuestros resultados no se correspondan con los de Park y Henley (2007), los resultados encontrados sí muestran coherencia y consideramos que la cuestión debe ser objeto de mayor investigación en el futuro: las tres clases del cuarto grupo realizan una labor de avanzadilla en un grupo de juego de $D \& D$, enfrentándose los primeros a los peligros, entablando interacciones con los personajes del Director de Juego, y protegiendo a sus compañeros, aspectos que podemos relacionar con los factores de personalidad Apertura a la Experiencia, Extraversión y Amigabilidad respectivamente.

Por lo que respecta a las asociaciones esperadas entre raza, clase y características, encontramos que tanto en la relación entre raza y clase como raza y características los resultados son los esperados por el juego $D \& D$ : los jugadores prefieren razas que por su planteamiento se asocian con determinadas clases, y también prefieren características de acuerdo con la clase que deciden desempeñar (p. ej. los guerreros prefieren características físicas, los magos mentales). Destaca que en el grupo tercero, formado mayoritariamente por clases que precisan de puntuaciones altas tanto en características físicas como mentales, las preferencias se repartieron al cincuenta por ciento entre ambos tipos de características.

Con respecto a la última de las hipótesis, referente al peso de determinados elementos dentro del argumento de la historia, se ha encontrado que las personas extravertidas prefieren el misterio en sus partidas, todo lo contrario que las personas que puntúan alto en Amigabilidad y las que lo hacen en Neuroticismo, quienes además prefieren incluir escenas de acción en sus partidas. Estos resultados parecen guardar relación con el modo en que se desarrollan las partidas, ya que en las que tienen un mayor peso de misterio es preciso dialogar continuamente (entre jugadores para intercambiar ideas, con el Director de Juego para descubrir pistas), algo que puede gustar a las personas con una elevada Extraversión, mientras que el combate suele requerir de trabajo en equipo y la definición de las tareas a realizar en el combate (quién ataca a quién y de qué forma, etc.) para derrotar a los enemigos, algo apropiado para las preferencias de una persona amigable, que gusta del trabajo en equipo, y de una persona con Neuroticismo alto, que prefiere tareas claras y bien definidas. No obstante estas asociaciones y nuestras explicaciones son puramente exploratorias y consideramos que requieren de mayor investigación en el futuro.

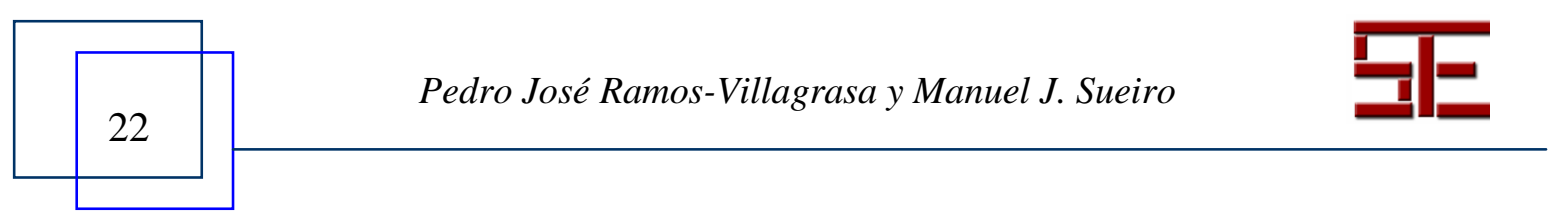




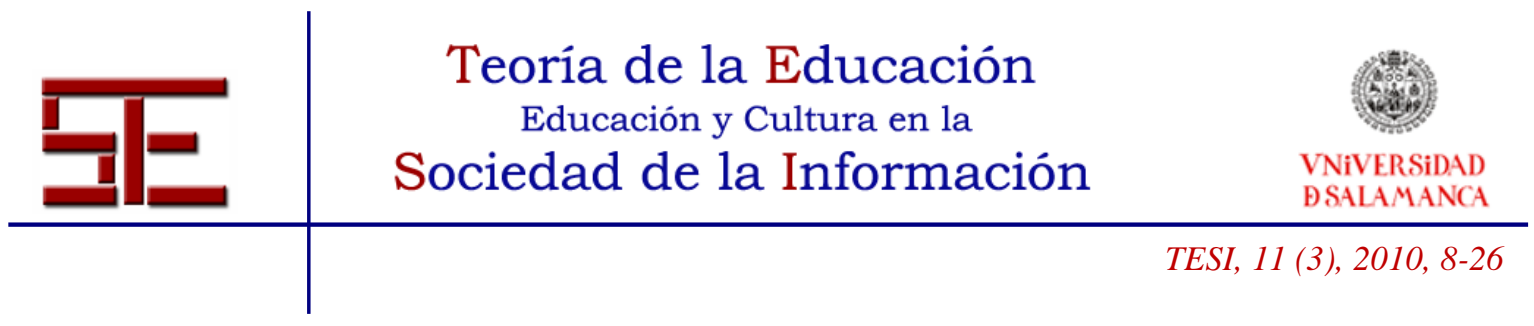

\section{1.- Limitaciones del estudio y recomendaciones para la investigación futura}

Las principales limitaciones del estudio se encuentran en el tamaño de la muestra. En nuestro caso, esto obligó a agrupar las razas y clases para poder realizar los análisis MANOVA. Esto ha podido distorsionar los análisis, enmascarando determinadas relaciones al agrupar razas y clases que, aunque semejantes, no son idénticas.

También encontramos que el colectivo de jugadores de rol en España es reducido, y posteriores investigaciones deberían esforzarse por acceder a una muestra representativa y con un tamaño suficiente para realizar análisis más exhaustivos. Sólo así se podrá analizar las diferencias entre razas y clases específicas y continuar indagando acerca de la relación entre personalidad y elección de personaje.

Junto a ello, también deseamos destacar que estos resultados se refieren específicamente al juego de rol $D \& D$. Posteriores investigaciones podrían explorar la elección de personaje en otros juegos de rol, siendo un resto especialmente interesante aquellos juegos donde no existen "arquetipos" como son las razas o clases de $D \& D$.

Por último, deseamos reivindicar la investigación científica sobre los juegos de rol en psicología, tanto para conocer más y mejor los aspectos que rodean el juego, como para obtener un mayor conocimiento del modo en que las personas encaramos situaciones ficticias. Los juegos de rol tienen un fuerte componente de simulación, de plantearse situaciones hipotéticas, en el que los autores de este trabajo no podemos evitar contemplar cierta similitud con determinadas pruebas psicológicas que evalúan la respuesta de las personas ante situaciones hipotéticas. Un mayor conocimiento de los procesos psicológicos que determinan las respuestas a estas situaciones en los juegos de rol facilitaría la valoración de las respuestas en estas pruebas.

\section{Agradecimientos}

Agradecemos a la Asociación Juvenil "Odisea Astur" y a "NSR Ediciones" su contribución durante la recogida de muestra para esta investigación.

\section{8.- BIBLIOGRAFÍA}

Abyeta, S. y Forest, J. (1991). Relationship of role-playing games to self-reported criminal behaviour. Psychological Reports, 69 (3), 1187-1192.

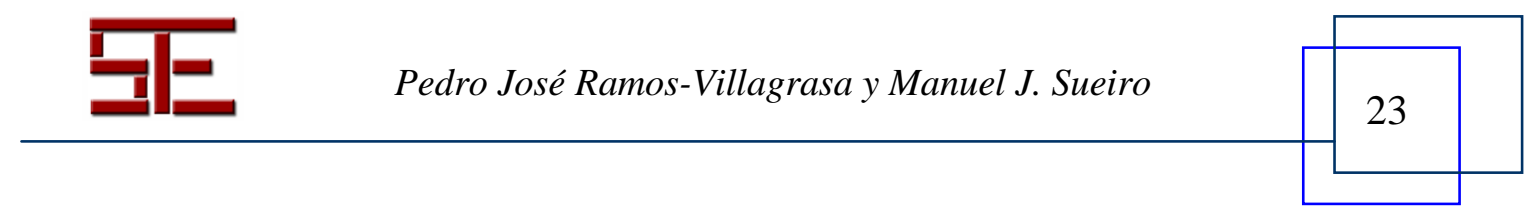




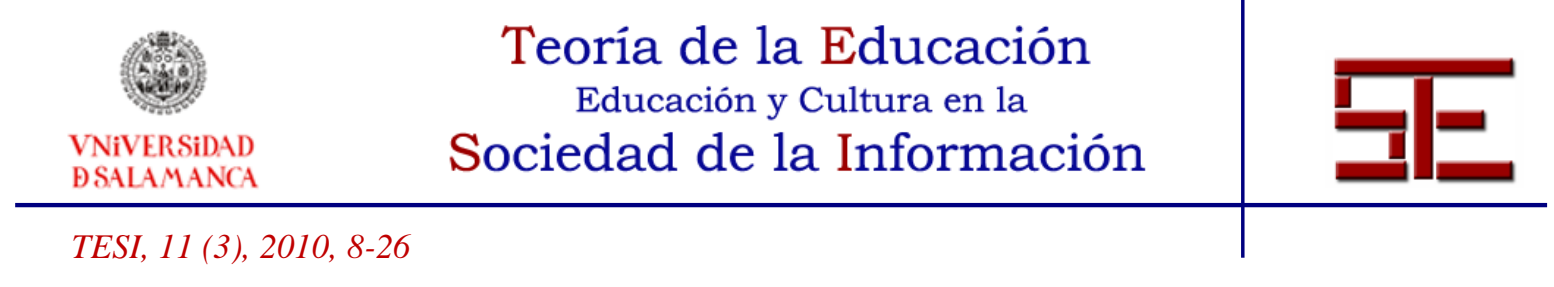

Allport, G. (1937). Personality: a psychological interpretation. New York, NY: Henry Holt.

Benet-Martínez, V. (1997). Theoretical perspectives on the five factor model: Agreement about five factors, disagreement about the concept. Journal of Personality Assessment, 69, 658-664.

Block, J. (1995). A contrarian view of the five-factor approach to personality description. Psychological Bulletin, 177, 187-215.

Camargo, M. E., Jacobi, P. R. y Ducrot, R. (2007). Role-playing games for capacity building in water and land management: some brazilian experiences. Simulation \& Gaming, 38 (4), 472-493.

Cole, H. y Griffiths, M. D. (2007). Social interactions in massively multiplayer online role-playing gamers. CyberPsychology \& Behavior, 10 (4), 575-583.

Cook, M., Williams, S. y Tweet, J. (2003). Monster Manual. Renton: Wizards of the Coast.

De Freitas, S. y Griffiths, M. (2007). Online gaming as an educational tool in learning and training. British Journal of Educational Technology, 38 (3), 535-537.

Dyszelski, C. J. (2006). Encounters at the imaginal crossroads: An exploration of the experiences of women in role-playing games. Dissertation Abstracts International: Section B: The Sciences and Engineering, 67, 2221.

Enfield, G. (2007). Becoming the hero: The use of role-playing games in psychotherapy. En L. C. Rubin (ed.), Using superheroes in counseling and play therapy (pp. 227-241). New York: Springer.

Esteban, A. y Vecina, M. L. (1999). Efectos psicológicos de los juegos de rol en el desarrollo social y cognitivo de los menores. Madrid: Colegio Oficial de Psicólogos de Madrid.

Goldberg, L. R. (1990). An alternative 'description of personality': The Big-Five factor structure. Journal of Personality and Social Psychology, 59 (6), 1216-1229.

Gygax, G. y Anderson, D. (1974). Dungeons \& Dragons. Lake Geneva: TSR Inc.

Hammer, J. (2007). Agency and authority in role-playing 'texts'. En M. Knobel y C. Lankshear (Eds.), A new literacies sampler (pp.67-93). New York: Peter Lang Publishing.

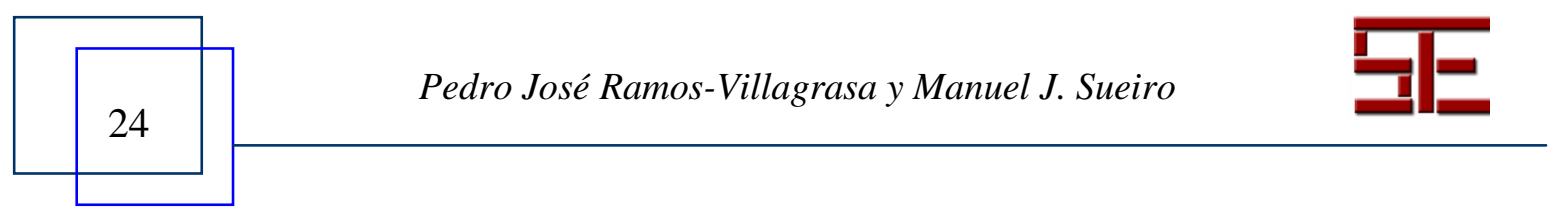




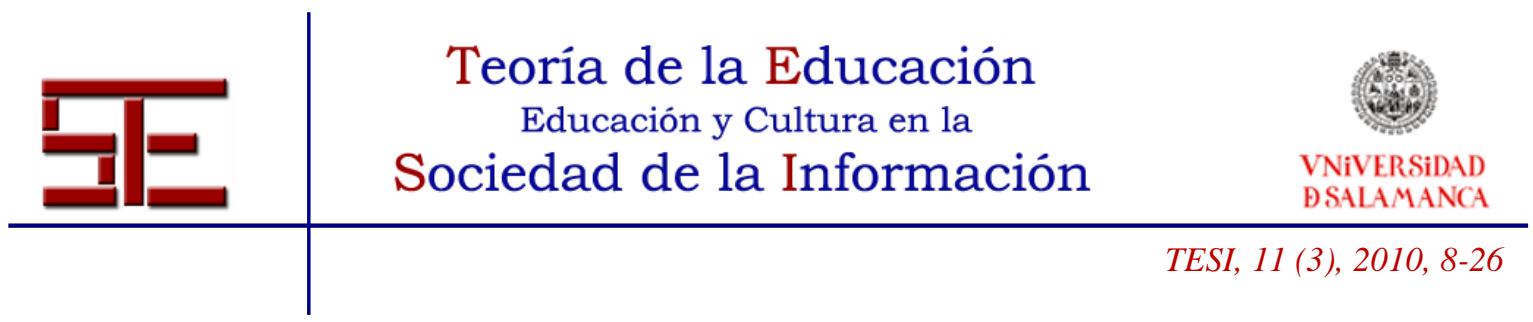

Hitchens, M. y Drachen, A. (2008). The Many Faces of Role-Playing Games. International Journal of Role-Playing, 1, 3-21.

Hsu, S. H., Kao, C., y Wu, M. (2007). Factors Influencing Player Preferences for Heroic Roles in Role-Playing Games. CyberPsychology \& Behavior, 10 (2), 293-295.

John, O. P. (1990). The "Big Five" factor taxonomy: Dimensions of personality in the natural language and in questionnaires. En L. A. Pervin (Ed.), Handbook of personality: Theory and research (pp 66-100). NewYork: Guilford Press.

John, O. P. y Robins, R. W. (1993). Gordon Allport: Father and critic of the five-factor model. En K. H. Craik, R. Hogan y R. N. Wolfe (Eds.), Fifty years of personality psychology (pp 215-236). Newark: Plenum.

Jokela, M., Kivimäki, M. Elovainio, M. y Keltikangas-Järvinen, L. (2009). Personality and having children: A two-way relationship. Journal of Personality and Social Psychology, 96 (1), 218-230.

Leeds, S. M. (1995). Personality, belief in the paranormal, and involvement with satanic practices among young adult males: Dabblers versus gamers. Cultic Studies Journal, 12 (2), 148-165.

Mackay, D. (2001). The Fantasy Role-Playing Game: A New Performing Art. Raleigh, NC: McFarland \& Company, Inc., Publishers.

Park, A. y Henley, T.B. (2007). Personality and Fantasy Game Character Preferences. Imagination, Cognition and Personality, 27(1), 37-46.

Rentfrow, P. J. y Gosling, S. D. (2003). The do re mi's of everyday life: The structure and personality correlates of music preferences. Journal of Personality and Social Psychology, 84 (6), 1236-1256.

Rivers, A. (2007). Empathic aspects of absorption and fantasy proneness in fantasy role players. Dissertation Abstracts International: Section B: The Sciences and Engineering, 67, 4116.

Schoen, H. y Schumann, S. (2007). Personality traits, partisan attitudes, and voting behavior. Evidence from Germany. Political Psychology, 28(4), 471-498.

Simón, A. (1998). Emotional stability pertaining to the game Vampire: The Masquerade. Psychological Reports, 83 (2), 732-734.

Tweet, J., Cook, M. y Williams, S. (2003). Player's Guide. Renton: Wizards of the Coast.

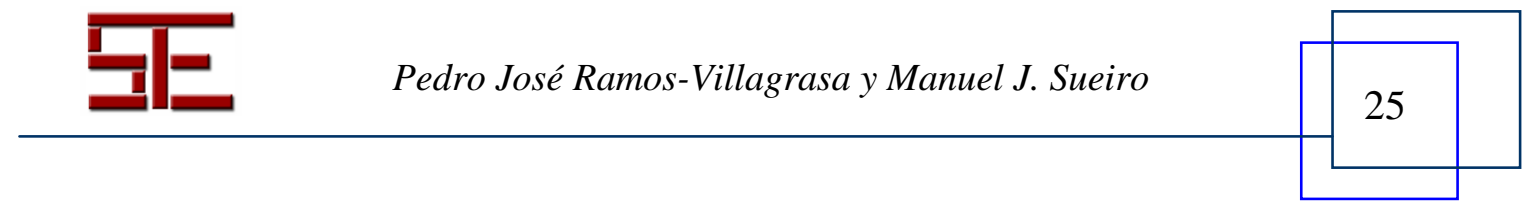




\section{Teoria de la Educación}

Educación y Cultura en la

Williams, S., Tweet, J. y Cook, M. (2003). Dungeon Master's Guide. Renton: Wizards of the Coast.

Zimmerman, R.D. (2008). Understanding the impact of personality traits on individuals' turnover decisions: A meta-analytic path model. Personnel Psychology, 61 (2), 309348.

Para citar el presente artículo puede utilizar la siguiente referencia:

Ramos Villagrasa, P.J. y Sueiro M. J (2010). Personalidad y elección de personaje en los juegos de rol: dime quién eres y te diré quien prefieres ser, en Orejudo González, J.P. (Coord.) Perspectiva educativa y cultural de "juego de rol". Revista Teoría de la Educación: Educación y Cultura en la Sociedad de la Información. Vol. 11, no 3. Universidad de Salamanca, pp. 8-26 [Fecha de consulta: dd/mm/aaaa]. http://campus.usal.es/ revistas_trabajo/index.php/revistatesi/article/view/7443/7459 